\title{
Dopamine D4 Receptor-Knock-Out Mice Exhibit Reduced Exploration of Novel Stimuli
}

\author{
Stephanie C. Dulawa, ${ }^{1}$ David K. Grandy, ${ }^{3}$ Malcolm J. Low, ${ }^{4}$ Martin P. Paulus, ${ }^{2}$ and Mark A. Geyer ${ }^{1,2}$ \\ Departments of ${ }^{1}$ Neuroscience, and ${ }^{2}$ Psychiatry, University of California at San Diego, La Jolla, California 92093-0804, \\ ${ }^{3}$ Department of Physiology and Pharmacology, and ${ }^{4}$ Vollum Institute, Oregon Health Sciences University, Portland, \\ Oregon 97201
}

The involvement of dopamine neurotransmission in behavioral responses to novelty is suggested by reports that reward is related to increased dopamine activity, that dopamine modulates exploratory behavior in animals, and that Parkinson's disease patients report diminished responses to novelty. Some studies have reported that polymorphisms of the human dopamine D4 receptor (D4R) gene are associated with personality inventory measures of the trait called "novelty-seeking". To explore a potential role for the D4R in behavioral responses to novelty, we evaluated D4R-knock-out (D4R-/-) and wild-type $(\mathrm{D} 4 \mathrm{R}+/+)$ mice in three approach-avoidance paradigms: the open field, emergence, and novel object tests. These three paradigms differ in the degree to which they elicit approach, or exploratory behavior, and avoidance, or anxiety-related behav- ior. Thus, we used these three tests to determine whether the D4R primarily influences the exploratory or the anxious component of responses to approach-avoidance conflicts. $\mathrm{D} 4 \mathrm{R}-/$ - mice were significantly less behaviorally responsive to novelty than $\mathrm{D} 4 \mathrm{R}+/+$ mice in all three tests. The largest phenotypic differences were observed in the novel object test, which maximizes approach behavior, and the smallest phenotypic differences were found in the open field test, which maximizes avoidance behavior. Hence, D4R-/- mice exhibit reductions in behavioral responses to novelty, reflecting a decrease in novelty-related exploration.

Key words: novelty; D4 receptor; exploration; approachavoidance; mice; anxiety; open field
Much interest in the dopamine D4 receptor (D4R) has been generated recently because of reports that specific tandem repeat polymorphisms of the human D4R gene correlate with higher than average novelty-seeking scores on questionnaires (Benjamin et al., 1996; Ebstein et al., 1996), although others have been unable to replicate these findings (Malhotra et al., 1996; Vandenbergh et al., 1997; Kuhn et al., 1999). To examine a potential role for the D4R in behavioral responses to novelty, D4R $+/+$ and D4R-/- mice (Rubinstein et al., 1997) were assessed in three approach-avoidance conflicts: the open field, emergence, and novel object tests.

Novel stimuli, such as unfamiliar environments or objects, are theorized to create conflict in rodents by concurrently evoking both approach and avoidance behaviors (Montgomery, 1955; Dember, 1956; Welker, 1957; Berlyne, 1960). Approach behavior or "exploration" reflects an animal's tendency to explore novel stimuli or environments, whereas avoidance behavior or "anxietyrelated behavior" is thought to reflect an animal's fear of novelty. Because novel stimuli elicit this approach-avoidance conflict, phenotypic differences in behavioral responses to novelty cannot

\footnotetext{
Received Aug. 3, 1999; accepted Aug. 4, 1999.

This work was supported by the National Institute on Drug Abuse (NIDA) (Grants R01DA11277, R02DA02925, and R21DA09620), the National Alliance for Research on Schizophrenia and Depression, and the United States Veterans Affairs and VISN22 Mental Illness Research, Education, and Clinical Center. S.C.D. was supported by a minority supplement from NIDA (R02DA02925). M.A.G. holds an equity interest in San Diego Instruments, Inc. We thank Dr. Lisa Gold for advice regarding behavioral tests, Dr. Athina Markou for helpful comments on this manuscript, and both Jennifer Larson and Elizabeth Lutz for technical assistance.

Correspondence should be addressed to Dr. Mark A. Geyer, Department of Psychiatry 0804, University of California at San Diego, 9500 Gilman Drive, La Jolla, CA 92093-0804. E-mail: mgeyer@ucsd.edu.

Copyright (C) 1999 Society for Neuroscience $0270-6474 / 99 / 199550-07 \$ 05.00 / 0$
}

be interpreted as indicative of changes in either exploratory drive or anxiety unless the relative contributions of these competing tendencies is manipulated by varying the testing environment. The three tests used here were selected based on their ability to elicit these two behavioral dimensions differentially in rodents by providing varying degrees of stimulus novelty and escape potential within the same environmental context. Comparisons of effect sizes observed across these three tests can provide converging evidence of a phenotypic difference in either approach or avoidance responses to novelty.

The open field test, which is the most anxiety-provoking of the three tests, is thought to induce moderate anxiety (Welker, 1957; Hennessy et al., 1979; Belzung, 1992) by confronting rodents with a novel environment with no possibility of escape. By contrast, the emergence test is a free exploration paradigm designed to reduce anxiety by providing a safe enclosure within the open field in order to assess approach or exploratory behavior in rodents (Welker, 1957; Misslin and Cigrand, 1986). The novel object test (Belzung, 1992; Renner et al., 1992) is another free exploration paradigm, which elicits the most approach or exploration of the three tests by presenting animals with the most novel stimuli (Berlyne, 1960; Fowler, 1965; Berlyne and Slater, 1969; Dutch and Brown, 1971) in a familiar environmental context. By comparing the effect sizes of phenotypic differences in the three tests, it is possible to disentangle the potential role of the D4R in exploratory behavior from its potential role in anxiety-related behavior (Montgomery, 1955).

\section{MATERIALS AND METHODS}

Subjects

D4R +/+ and D4R -/- mice (Oregon Health Sciences University, Portland, OR) were 8-week-old F2s (C57BL/6J × 129Sv/Ola) that weighed 
20-40 gm. Mice were maintained on a $12 \mathrm{hr}$ light/dark schedule (lights off at 7:00 A.M.) and were housed in groups of four to five with same-type mice. Food and water were provided ad libitum. Behavioral testing occurred during the dark phase between 8:00 A.M. and 6:00 P.M. Two D4R $+/+$ and three $\mathrm{D} 4 \mathrm{R}-/-$ male mice were killed after the emergence test because of lacerations from fighting with cage-mates, and thus were not assessed in the novel object test. All animal testing was conducted in accord with the National Institutes of Health laboratory animal care guidelines and with local animal care committee approval. No sex differences were predicted; mice of either sex were used as available for all tests.

\section{Apparatus and procedures}

Motor activity was quantified using the Polytrack video system (San Diego Instruments, San Diego, CA). A video camera mounted centrally, $160 \mathrm{~cm}$ above the apparatus, monitored four separate $40-\mathrm{cm}$-long $\times$ 40 -cm-wide $\times 37$-cm-high white Plexiglas open fields, with one mouse in each field. A computer program was used to overlay grid lines that defined separate regions within each open field. Paths taken by each mouse were stored permanently as $x-y$ coordinate sequences. Overall locomotor activity was assessed as the total number of crossings between regions of the open field during the test session.

Open field test. $\mathrm{D} 4 \mathrm{R}+/+(n=18)$ and $\mathrm{D} 4 \mathrm{R}-/-(n=21)$ male mice were subjects. This cohort of mice was used only in the open field test. Mice were tested for 30 min on 3 separate test days, each separated by $1 \mathrm{~d}$ of rest. The computer defined grid lines that divided each open field into

\section{Open Field Test}

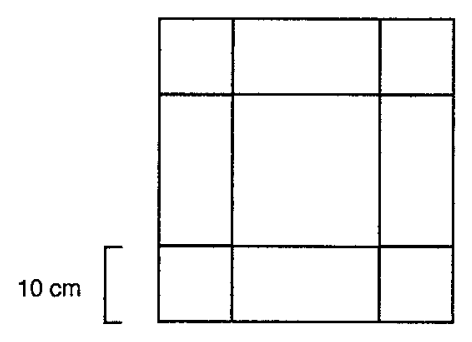

Emergence Test



Novel Object Test

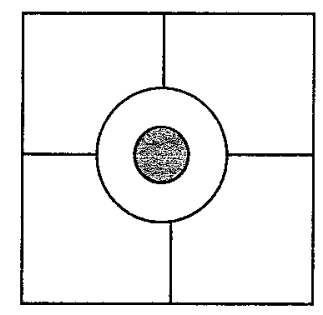

Figure 1. Regions within the open field apparatus for the open field, emergence, and novel object tests formed by computer overlaid grid lines (as viewed from above). The gray rectangle in the emergence test represents the cylinder; the gray circle in the novel object test represents the novel cup. nine separate regions: four corner regions, four wall or "side" regions, and one square region in the center, with each of four lines being $10 \mathrm{~cm}$ from each wall (Fig. 1). We assessed the number of entries into the center, and the total time spent in the center. Overall motor activity was quantified as the total number of crossings between the nine regions of the open field.

Emergence test. $\mathrm{D} 4 \mathrm{R}+/+$ (28 female, 33 male) and $\mathrm{D} 4 \mathrm{R}-/-(29$ female, 46 male) mice were subjects. Each open field contained an aluminum cylinder (10-cm-deep and $6.5 \mathrm{~cm}$ in diameter) located lengthwise along one wall, with the open end $10 \mathrm{~cm}$ from the corner. Mice were placed into the cylinder and tested for $15 \mathrm{~min}$. A trained observer blind to genotype scored the following behaviors: the latency to leave the cylinder, defined as placement of all four paws into the open field; the number of entries into the cylinder with the initial placement counting as an entry; the total time spent inside the cylinder; and the mean time in the cylinder per entry (MTIC). The computer defined grid lines in the same manner as described for the open field test (Fig. 1). Overall motor activity was quantified as the total number of crossings between the nine regions of the open field.

Novel object test. After being used in the emergence test, the same mice [D4R $+/+$ (28 female, 33 male $)$ and $\mathrm{D} 4 \mathrm{R}-/-(29$ female, 46 male $)]$ mice were tested in the novel object test. Mice had been familiarized with the open field during the emergence test. Fourteen days later, mice were placed into the open field for $30 \mathrm{~min}$. Then, a novel paper cup measuring $9.5 \mathrm{~cm}$ in height and $7.5 \mathrm{~cm}$ in diameter at the rim was placed upsidedown into the center of each open field and was secured to the floor with tape placed inside the cups. Mice were tested for an additional $30 \mathrm{~min}$ with the cup. The computer defined grid lines that divided each open field into five separate regions: one circular region in the center with a diameter of $18 \mathrm{~cm}$ and a surrounding region that was divided into fourths by gridlines that extended from the middle of each wall to the edge of the center region (Fig. 1). The percentage of entries made into the center, the percentage of time spent in the center, and overall locomotor activity were assessed by an automated video-tracking system (Fig. 1). Overall motor activity was quantified as the total number of crossings between the five regions of the open field.

\section{Statistical analysis}

Open field test. Two-factor ANOVAs with genotype as a betweensubjects factor and day as a within-subjects factor were applied to three measures: the total time spent in the center, the number of entries into the center, and overall motor activity. A significant effect of day on overall motor activity was analyzed with post hoc one-way ANOVAs, with $\alpha$ levels adjusted appropriately.

Emergence test. Two-factor ANOVAs with genotype and sex as between-subjects factors were applied to each of five measures: latency to leave the cylinder, number of entries into the cylinder, total time spent inside the cylinder, MTIC, and overall motor activity. Significant interactions were analyzed with post hoc one-way ANOVAs, with $\alpha$ levels adjusted appropriately.

Novel object test. Three-factor ANOVAs with genotype and sex as between-subjects factors and environmental condition (with vs without cup) as a within-subjects factor were applied to three different measures:

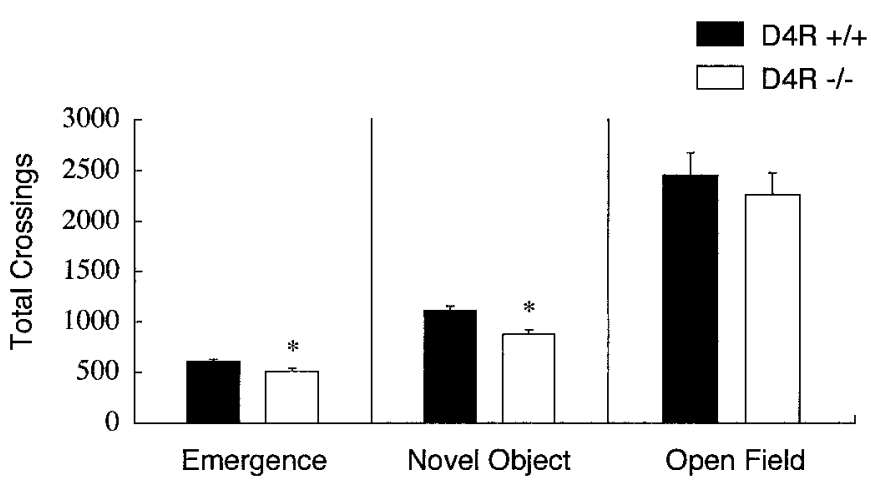

Figure 2. Motor activity. Total locomotor activity in the emergence, novel object, and open field tests is shown for D4R $+/+$ and D4R $-/-$ mice. Values are means \pm SEM. * $p<0.05$ versus $\mathrm{D} 4 \mathrm{R}+/+$ group with ANOVA. 


\begin{tabular}{|c|c|c|c|c|c|c|}
\hline & \multicolumn{6}{|c|}{ Mouse genotype } \\
\hline & \multicolumn{3}{|c|}{ Wild-type $(+/+)$} & \multicolumn{3}{|c|}{ D4R-Knock-out $(-/-)$} \\
\hline & Day 1 & Day 2 & Day 3 & Day 1 & Day 2 & Day 3 \\
\hline Crossings & $968 \pm 79$ & $794 \pm 85$ & $695 \pm 82$ & $876 \pm 85$ & $641 \pm 81$ & $754 \pm 76$ \\
\hline Center entries* & $130 \pm 18$ & $75 \pm 17$ & $84 \pm 18$ & $88 \pm 13$ & $47 \pm 11$ & $78 \pm 16$ \\
\hline Adjusted center entries** & $105 \pm 3$ & $73 \pm 3$ & $96 \pm 3$ & $75 \pm 2$ & $66 \pm 2$ & $83 \pm 2$ \\
\hline
\end{tabular}

Total crossings, center entries, and adjusted center entries, which account for the variance associated with crossings are shown for $\mathrm{D} 4 \mathrm{R}+/+(n=18)$ and $\mathrm{D} 4 \mathrm{R}-/-$ mice $(n=21)$. Values are means \pm SEM. The asterisk $(*)$ indicates that $\mathrm{D} 4 \mathrm{R}-/-$ mice made fewer center entries than $\mathrm{D} 4 \mathrm{R}+/+$ mice across all $3 \mathrm{~d}$. The double asterisks $(* *)$ indicate that this effect remained significant after ANCOVA assessed crossings as a covariate $(p<0.05)$.

percentage of entries into the center, percentage of time spent in the center, and overall locomotor activity. Significant interactions were analyzed using post hoc ANOVAs with adjusted $\alpha$ levels.

When significant phenotypic differences in locomotor activity were observed in any of the three test paradigms, ANCOVAs were applied to exploratory measures with locomotor activity as a covariate. Remaining significant differences between genotypes indicate independence between measures of locomotor activity and exploration. Effect size (ES) was calculated as the difference between means divided by the square root of the error mean square of the $F$ ratio (Cohen, 1988) for all exploratory measures with phenotypic differences.

\section{RESULTS}

\section{Open field test}

Mice were tested on 3 separate days in the open field, a forced exploration paradigm (Welker, 1957; Adams and Geyer, 1985; Belzung, 1992) in which escape from novelty is impossible. $\mathrm{D} 4 \mathrm{R}+/+$ and $\mathrm{D} 4 \mathrm{R}-/-$ mice showed no differences in locomotor activity over the $3 \mathrm{~d}$ of testing (Fig. 2). Both genotypes exhibited locomotor habituation over time, showing reduced levels of activity on the second $\left(F_{(1,76)}=6.52 ; p<0.01\right)$ and third $\left(F_{(1,76)}=\right.$ 6.04; $p<0.02$ ) days relative to the first day (Table 1$)$. D4R $-/-$ mice exhibited reduced behavioral responses to novelty relative to $\mathrm{D} 4 \mathrm{R}+/+$ mice, as indicated by fewer entries into the center $\left(F_{(1,111)}=4.4 ; p<0.04\right)$, and a trend to spend less time in the center $\left(F_{(1,111)}=3.14 ; p=0.08\right)$. The novelty of the center of the open field diminishes over time (Fowler, 1965), but its anxiogenic properties do not (Adams and Geyer, 1985). Therefore, entries into the center primarily reflect exploratory behavior on the first day of open field testing, but primarily reflect anxiety-related behavior after repeated testing. We assessed the effect size of the phenotypic difference in center entries for each day. The largest effect size was observed on the novel day of testing, and decreased each subsequent day: day one $(\mathrm{ES}=0.7)$, day two $(\mathrm{ES}=0.4)$, and day three $(E S=0.1)$. The phenotypic difference in center entries on day one primarily reflects a reduction in approach or exploratory behavior in $\mathrm{D} 4 \mathrm{R}-/-$ mice $(\mathrm{ES}=0.7)$, but on day three primarily reflects a reduction in anxiety in $\mathrm{D} 4 \mathrm{R}-/-$ mice $(\mathrm{ES}=0.1)$.

We applied an ANCOVA to center entries, with locomotor activity as a covariate, to assess whether phenotypic differences in behavioral responses to novelty and locomotor activity were independent. In the present experiment, ANCOVA revealed that the decreases in center entries exhibited by $\mathrm{D} 4 \mathrm{R}-/-$ mice remained significant, even after accounting for the variance associated with the levels of locomotor activity. Thus, D4R $-/-$ mice were less behaviorally responsive to novelty than $\mathrm{D} 4 \mathrm{R}+/+$ mice in $3 \mathrm{~d}$ of open field testing.

\section{Emergence test}

Mice were assessed in the emergence test, a free exploration paradigm (Welker, 1957; Adams and Geyer, 1985; Belzung and Le Pape, 1994) in which animals can explore the open field or retreat into a cylinder. D4R $-/-$ mice were less behaviorally responsive to the novel environment than $\mathrm{D} 4 \mathrm{R}+/+$ mice. Relative to $\mathrm{D} 4 \mathrm{R}+/+$ mice, $\mathrm{D} 4 \mathrm{R}-/-$ mice had significantly longer latencies to emerge from the cylinder $\left(F_{(1,132)}=4.62 ; p<0.03\right)$, spent significantly more total time inside the cylinder $\left(F_{(1,132)}=\right.$ $29.81 ; p<0.005)$, made fewer entries into the cylinder $\left(F_{(1,132)}=\right.$ 12.35; $p<0.002)$, and had significantly larger MTIC values $\left(F_{(1,132)}=6.12 ; p<0.02\right)$ (Fig. 3). Additionally, a significant genotype $\times$ sex interaction with respect to entries into the cylinder was indicated. Post hoc tests showed that D4R $+/+$ female mice made more transitions than $\mathrm{D} 4 \mathrm{R}+/+$ male mice $\left(F_{(1,60)}=\right.$ $21.57 ; p<0.0001)$ and D4R $-/-$ female mice $\left(F_{(1,56)}=15.43 ; p<\right.$ $0.0003)$, indicating that the reduction in entries into the cylinder exhibited by D4R-/- mice was caused by female mice (Fig. 4). $\mathrm{D} 4 \mathrm{R}-/-$ mice were also less active overall than $\mathrm{D} 4 \mathrm{R}+/+$ mice $\left(F_{(1,132)}=8.61 ; p<0.01\right)$ (Fig. 2). Female mice were less active overall $\left(F_{(1,132)}=5.04 ; p<0.03\right)(510.0 \pm 27.4$ vs $583.8 \pm 23.5)$ and spent more time in the cylinder $\left(F_{(1,132)}=9.16 ; p<0.004\right)$ than male mice, but these effects did not interact with genotype.

Appropriate ANCOVAs confirmed that the phenotypic differences for total time spent in $(E S=0.8)$ and number of entries into the cylinder $(\mathrm{ES}=0.5)$ remained significant, independent of the level of locomotor activity. In contrast, the phenotypic differences for latency to emerge and for MTIC values were no longer significant, indicating that the differences in these measures were directly related to motor activity levels. Additionally, the main effect of sex on time spent in the cylinder was also dependent on the differences in locomotor activity. Thus, D4R - / - mice exhibited reduced behavioral responses to novelty compared to $\mathrm{D} 4 \mathrm{R}+/+$ mice, as indicated by the measures of time spent in the cylinder and number of entries into the cylinder.

\section{Novel object test}

Mice were tested in the novel object test, a free exploration paradigm (Belzung, 1992; Renner et al., 1992; Belzung and Le Pape, 1994) that provides animals the opportunity to explore a novel object in a non-threatening and familiar environment. Both genotypes spent a higher percentage of time and made a higher percentage of entries into the center after introduction of the cup, confirming that the novel cup elicited approach behavior. Both genotypes made comparable increases in the percentage of center entries after introduction of the cup. Nevertheless, D4R $-/-$ mice were less behaviorally responsive to the novel cup than $\mathrm{D} 4 \mathrm{R}+/+$ 


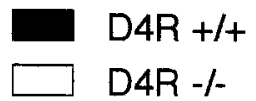

a.

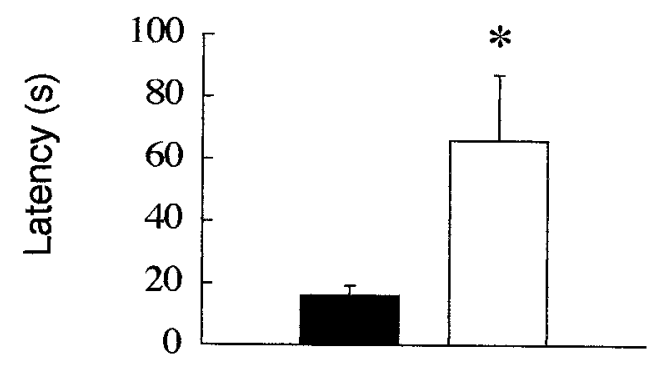

b.

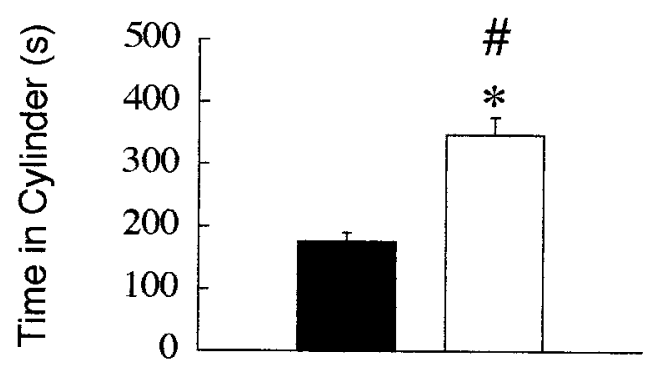

C.



d.

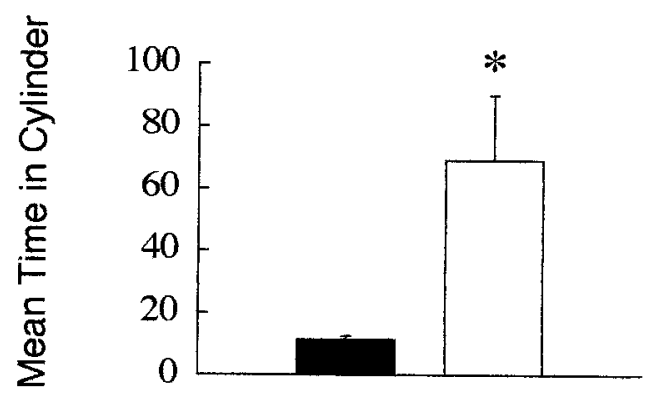

Figure 3. Emergence test. Exploratory measures of the emergence test are shown for $\mathrm{D} 4 \mathrm{R}+/+(n=61)$ and $\mathrm{D} 4 \mathrm{R}-/-$ mice $(n=75)$. The latency to emerge from the cylinder in seconds $(a)$, the total time spent in the cylinder in seconds $(b)$, the total number of entries into the cylinder $(c)$, and the MTIC in seconds $(d)$ are shown for both genotypes. Values are means \pm SEM. ${ }^{*} p<0.05$ versus $\mathrm{D} 4 \mathrm{R}+/+$ group with ANOVA; $\# p<$ 0.05 versus $\mathrm{D} 4 \mathrm{R}+/+$ group with ANCOVA.

mice (Fig. 5), because D4R - /- mice made a smaller increase in the percentage of time spent in the center after introduction of the cup than D4R $+/+$ mice $\left(F_{(1,127)}=19.24 ; p<0.0001\right)$. Post hoc tests indicated that, although both genotypes spent significantly more time in the center after introduction of the cup, $\mathrm{D} 4 \mathrm{R}-/-$ mice spent significantly less percent time in the center than $\mathrm{D} 4 \mathrm{R}+/+$ mice during this condition $\left(F_{(1,71)}=58.47 ; p<\right.$

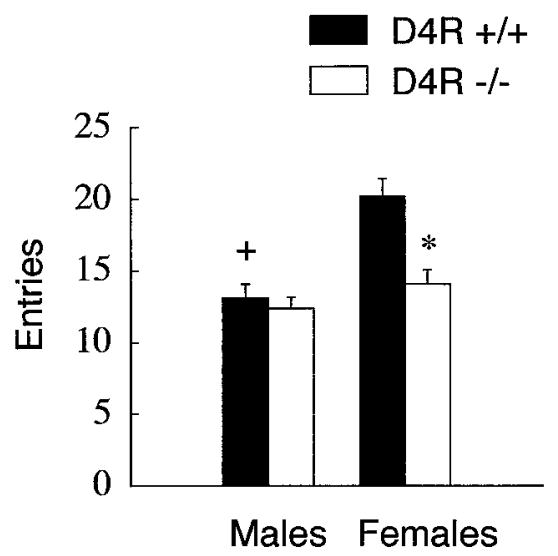

Figure 4. Cylinder entries: sex differences. The number of entries into the cylinder during the emergence test is shown for male $\mathrm{D} 4 \mathrm{R}+/+(n=$ $31)$, male $\mathrm{D} 4 \mathrm{R}-/-(n=43)$, female $\mathrm{D} 4 \mathrm{R}+/+(n=28)$, and female $\mathrm{D} 4 \mathrm{R}-/-$ mice $(n=29)$. Values are means \pm SEM. ${ }^{*} p<0.05$ versus female D4R $+/+$ group with ANOVA; $+p<0.05$ versus male D4R $+/+$ group with ANOVA.

a.
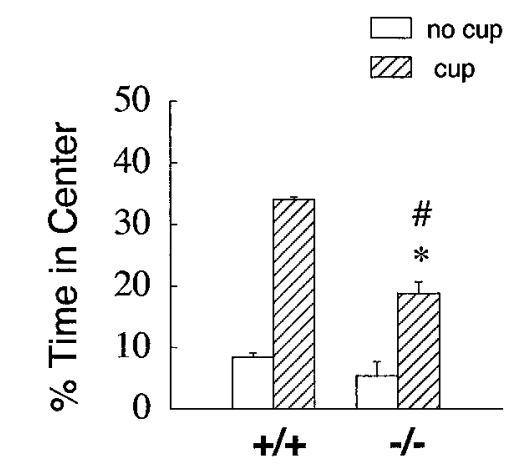

b.

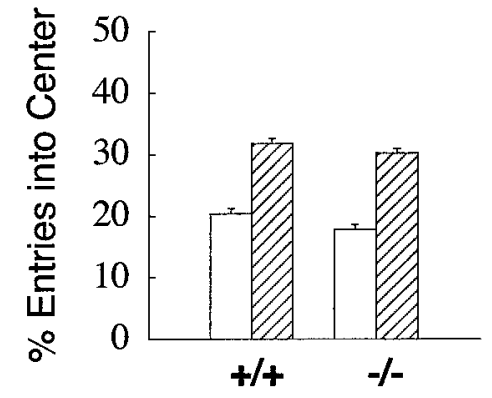

Figure 5. Novel object test. The percentage of time spent in the center region $(a)$ and the percentage of center entries $(b)$ are shown for $\mathrm{D} 4 \mathrm{R}+/+(n=59)$ and $\mathrm{D} 4 \mathrm{R}-/-$ mice $(n=72)$ for both environmental conditions of the novel object test. Values are means \pm SEM. ${ }^{*} p<0.05$ genotype $\times$ condition interaction with ANOVA; $\# p<0.05$ genotype $\times$ condition with ANCOVA.

0.0001). No interactions of sex and genotype were evident for these measures. Analyses using raw scores yielded the same conclusions as analyses using percentage scores for all measures. $\mathrm{D} 4 \mathrm{R}-/-$ mice were also less active overall than $\mathrm{D} 4 \mathrm{R}+/+$ mice $\left(F_{(1,127)}=12.18 ; p<0.0001\right)$ (Fig. 2). A sex difference in which female mice engaged in more locomotor activity than male mice was also observed $\left(F_{(1,127)}=6.19 ; p<0.01\right)(1079.7 \pm 53.6 \mathrm{vs}$ $906.3 \pm 42.0)$, but no interaction of sex and genotype was found.

Appropriate ANCOVAs testing for any relationship between locomotor activity and behavioral responses to novelty revealed that the increase in percentage of time spent in the center, after 
introduction of the cup, remained significantly decreased in $\mathrm{D} 4 \mathrm{R}-/-$ mice $(\mathrm{ES}=1.4)$. Thus, D4R $-/-$ mice exhibited independent reductions in locomotor activity and behavioral responses to novelty relative to $\mathrm{D} 4 \mathrm{R}+/+$ mice in the novel object test.

\section{DISCUSSION}

Here we report that mice lacking the D4R exhibit reduced behavioral responses to novelty. In the open field test, D4R-/mice made fewer entries into the center, but did not differ in overall levels of activity compared to $\mathrm{D} 4 \mathrm{R}+/+$ mice. In the emergence test, $\mathrm{D} 4 \mathrm{R}-/-$ mice spent more time in the cylinder and made fewer entries into the cylinder than $\mathrm{D} 4 \mathrm{R}+/+$ mice. In the novel object test, D4R-/- mice made a smaller increase in percentage of time spent in the center after introduction of the cup relative to $\mathrm{D} 4 \mathrm{R}+/+$ mice. We have also replicated these basic findings in an independent group of mice $(n=61)$ (data not shown). These three tests were used to explore the extent to which changes in exploratory drive or anxiety accounted for the phenotypic differences in response to approach-avoidance conflicts. Differences in approach or exploratory behavior appear to account for much of the behavioral phenotype, rather than avoidance or anxiety-related behaviors, because the effect size was largest in the novel object test $(\mathrm{ES}=1.4)$, intermediate in the emergence test $(\mathrm{ES}=0.8,0.5)$, and smallest in the open field test $(E S=0.1)$. The effect size for center entries on day three of the open field test was used for comparison because this measure primarily reflects avoidance or anxiety-related behavior, whereas center entries on day one are more indicative of approach or exploratory behavior. We also assessed effect sizes without including females to avoid any confound of sex, because only males were used in the repeated open field test. A similar pattern of effect sizes resulted for the novel object $(\mathrm{ES}=1.5)$, emergence $(\mathrm{ES}=0.8,0.1)$, and open field tests $(\mathrm{ES}=0.1)$. Thus, compared to $\mathrm{D} 4 \mathrm{R}+/+$ mice, $\mathrm{D} 4 \mathrm{R}-/-$ mice exhibited the largest reductions in behavioral responses to novelty in the test that is maximally sensitive to approach behaviors (the novel object test), and the smallest reductions in the test that is most reflective of avoidance behavior (the open field test).

Our hypothesis that the D4R is involved in modulating behavioral responses to novelty in mice derived from observations of an association between polymorphisms of the D4R gene and personality inventory measures of the trait called novelty-seeking (Benjamin et al., 1996; Ebstein et al., 1996). Our finding that knock-out of the D4R results in diminished behavioral responses to novelty in mice is consistent with the hypothesis that a lack of D4R function may lead to decreased novelty-seeking in humans. A direct link, however, cannot be made between the present results and the findings of the human association studies (Benjamin et al., 1996; Ebstein et al., 1996), because mice were either wild-type or D4R-deficient, whereas the human subjects possessed different D4R alleles for which there is evidence for varying function (Asghari et al., 1995). A null allele for the D4R has been reported to occur in $2 \%$ of the general population (Nothen et al., 1994). Comparing the novelty-seeking trait in subjects with the null D4R allele to those with functional alleles could directly test the hypothesis that lack of function of the D4R is associated with diminished novelty-seeking in humans. The same D4R alleles associated with novelty-seeking have recently been associated with behavioral disorders suggested to be related to novelty-seeking, such as drug abuse (Kotler et al., 1997; Shields et al., 1998), pathological gambling (de Castro et al., 1997), and attention deficit hyperactivity disorder (LaHoste et al., 1996;
Faraone et al., 1999). Further knowledge regarding the functional role of the D4R in behavioral responses to novelty could be an important step toward understanding the neurobiology of these disorders.

Mice lacking the D4R exhibited modest reductions in locomotor activity in the open field (nonsignificant), emergence, and novel object tests that were independent from the decreases in behavioral responses to novelty, as revealed by ANCOVA. This decrease in locomotor activity does not appear to result from a gross motor impairment, because $\mathrm{D} 4 \mathrm{R}-/-$ mice have been reported to outperform $\mathrm{D} 4 \mathrm{R}+/+$ mice on the rotarod and are supersensitive to the locomotor-activating effects of ethanol, cocaine, and methamphetamine (Rubinstein et al., 1997). It has been widely reported that the vulnerability of rats to drugs of abuse can be predicted by their locomotor response to a novel environment (Hooks et al., 1991, 1994), with high responders to novelty acquiring amphetamine self-administration more readily (Piazza et al., 1989) and exhibiting greater behavioral activation in response to amphetamine (Hooks and Kalivas, 1994). One might predict that because D4R $-/-$ mice exhibit less locomotor activity in a novel environment, they would show less behavioral activation to drugs of abuse than $\mathrm{D} 4 \mathrm{R}+/+$ mice. The supersensitivity of D4R - / - mice to the locomotor activation produced by ethanol, cocaine, and methamphetamine is thus surprising.

Phenotypes exhibited by knock-out mice of a mixed genetic background can result from the introduction of background genes linked to the mutated gene, rather than from the mutation itself. The present D4R - / - mice were generated using 129Sv/Ola stem cells crossed onto a C57BL/6 background (Rubinstein et al., 1997). The 129Sv/Ola strain performs normally relative to C57BL/6 mice in the open field test, the Morris water maze, the plus maze, and on coordination tests (Montkowski et al., 1997). In addition, 129Sv/Ola mice spend more time in the center of a novel open field than C57BL/6 mice (Montkowski et al., 1997), suggesting that the decrease in behavioral responses to novelty exhibited by $\mathrm{D} 4 \mathrm{R}-/-$ mice is not caused by $129 \mathrm{~Sv} /$ Ola background genes. A priori hypotheses reduce the likelihood of false positives when characterizing knock-out mice on a mixed background. The present experiments were undertaken to test the hypothesis the D4R is involved in modulating behavioral responses to novelty. Although it is conceivable that the reduction in behavioral responses to novelty observed in the $\mathrm{D} 4 \mathrm{R}-/-$ mice results from $129 \mathrm{~Sv} / \mathrm{Ola}$ background genes, the observed phenotype is most likely caused by lack of the D4R. It will be important to confirm these findings in congenic strains of $\mathrm{D} 4 \mathrm{R}+/+$ and $\mathrm{D} 4 \mathrm{R}-/-$ mice.

Differences in dopamine neurotransmission in $\mathrm{D} 4 \mathrm{R}-/-$ mice are localized to brain areas that could mediate the observed reductions in behavioral responses to novelty. Although dopaminergic neurons of the substantia nigra provide most of the dopaminergic projections to the dorsal striatum, these neurons do not express D4Rs. Rather, D4Rs are densely localized on glutamatergic pyramidal cells of frontal cortex (Mrzljak et al., 1996; Ariano et al., 1997; Rubinstein et al., 1997) that project to the dorsal striatum and the substantia nigra (Carter, 1982). The stimulation of nigrostriatal nerve terminals (Westerink et al., 1992) in the dorsal striatum or of nigral neurons by glutamate induces dopamine release (Overton and Clark, 1992). Accordingly, dopamine synthesis and its conversion to DOPAC are increased in the dorsal striatum of $\mathrm{D} 4 \mathrm{R}-/-$ mice (Rubinstein et al., 1997). Thus, frontal cortical D4Rs may alter the activity of nigrostriatal dopamine neurons by modulating the release of glutamate onto these neurons. Furthermore, D4Rs in the frontal 
cortex are likely to be under substantial influence of both noradrenergic inputs and dopaminergic inputs, because dopamine is only fivefold more potent at this receptor than epinephrine and norepinephrine, whereas dopamine is $>100$-fold more potent at D2 receptors than epinephrine and norepinephrine (Lanau et al., 1997).

Although effects of sex were neither predicted nor systematically studied in the present experiments, some sex differences in behavior were found. Female mice were more active overall than males in the novel object test, which is consistent with numerous reports that female mice are more active than male mice in many testing situations (Norton, 1977). However, in the emergence test, females were less active than males and spent more time in the cylinder than males, although an ANCOVA showed that these two effects were related. Only one interaction of genotype and sex was observed, in which female but not male D4R - / - mice made fewer entries into the cylinder than $\mathrm{D} 4 \mathrm{R}+/+$ mice in the emergence test. In both humans and rats, the modulation of the mesostriatal dopamine system and related behaviors by estrogen has been reported (Van Hartesveldt and Joyce, 1986), however, the human D4R association studies on novelty seeking have not reported gender effects (Benjamin et al., 1996; Ebstein et al., 1996; LaHoste et al., 1996; Kotler et al., 1997; de Castro et al., 1997; Shields et al., 1998; Faraone et al., 1999). Similarly, the important phenotypic differences observed in the present experiments did not interact significantly with the sex differences.

Our findings support the hypothesis positing a functional role for the D4R in behavioral responses to novelty. These results complement human genetic association studies implicating D4R polymorphisms in naturally occurring variations in the personality trait known as novelty seeking. Although it cannot be concluded that D4R-deficient mice are without abnormalities with regard to avoidance or anxiety-related behaviors, the present results are best explained by a reduction in approach or exploratory behavior. In conclusion, the D4R plays a role in modulating approach-avoidance responses in general and novelty-related exploration in particular.

\section{REFERENCES}

Adams LM, Geyer MA (1985) A proposed animal model for hallucinogens based on LSD's effects on patterns of exploration in rats. Behav Neurosci 99:881-900.

Ariano MA, Wang J, Noblett KL, Larson ER, Sibley D (1997) Cellular distribution of the rat $\mathrm{D}_{4}$ dopamine receptor protein in the CNS using anti-receptor antisera. Brain Res 752:26-34.

Asghari V, Sanyal S, Buchwaldt S, Paterson A, Jovanovic V, Van Tol HH (1995) Modulation of intracellular cyclic AMP levels by different human dopamine D4 receptor variants. J Neurochem 65:1157-1165.

Belzung C (1992) Hippocampal mossy fibres: implication in novelty reactions or in anxiety behaviors? Behav Brain Res 51:149-155.

Belzung C, Le Pape G (1994) Comparison of different behavioral test situations used in psychopharmacology for measurement of anxiety. Physiol Behav 56:623-628.

Benjamin J, Li L, Patterson C, Greenberg BD, Murphy DL, Hamer DH (1996) Population and familial association between the D4 dopamine receptor gene and measures of novelty seeking. Nat Genet 12:81-84.

Berlyne DE (1960) Conflict, arousal, and curiosity. New York: McGraw-Hill.

Berlyne DE, Slater J (1969) Explorations in exploration. New York: Van Nostrand Reinhold.

Carter CJ (1982) Topographical distribution of possible glutamatergic pathways from the frontal cortex to the striatum and substantia nigra in rats. Neuropharmacology 21:379-383.

de Castro PI, Ibanez A, Torres P, Saiz-Ruiz J, Fernandez-Piqueras J (1997) Genetic association study between pathological gambling and a functional DNA polymorphism at the D4 receptor gene. Pharmacogenetics 7:345-348.

Cohen J (1988) Statistical power analysis for the behavioral sciences. Hillsdale, NJ: Lawrence Erlbaum.

Dember WN (1956) Response by the rat to environmental change. J Comp Physiol Psychol 49:93-95.

Dutch J, Brown LB (1971) Visual stimulus complexity and approach behavior in rats. Psychonom Sci 22:162-63.

Ebstein RP, Novick O, Umansky R, Priel B, Osher Y, Blaine D, Bennett ER, Nemanov L, Katz M, Belmaker RH (1996) Dopamine D4 receptor (D4DR) exon III polymorphism associated with the human personality trait of novelty seeking. Nat Genet $12: 78-80$.

Faraone SV, Biederman J, Weiffenbach B, Keith T, Chu MP, Weaver A, Spencer TJ, Wilens TE, Frazier J, Cleves M, Sakai J (1999) Dopamine D4 gene 7-repeat allele and attention deficit hyperactivity disorder. Am J Psychiatry 156:768-770.

Fowler H (1965) Curiosity and exploratory behavior. New York: Macmillan.

Hennessy MB, Heybach JP, Vernikos J, Levine S (1979) Plasma corticosterone concentrations sensitively reflect levels of stimulus intensity in the rat. Physiol Behav 22:821-825.

Hooks MS, Kalivas PW (1994) Involvement of dopamine and excitatory amino acid transmission in novelty-induced motor activity. J Pharmacol Exp Ther 269:976-988.

Hooks MS, Jones GH, Smith AD, Neill DB, Justice JB (1991) Response to novelty predicts the locomotor and nucleus accumbens dopamine response to cocaine. Synapse 9:121-128.

Hooks MS, Juncos JL, Justice JB, Meiergerd CM, Povlock SL, Schenk JO, Kalivas PW (1994) Individual locomotor response to novelty predicts selective alterations in D1 and D2 receptors and mRNAs. J Neurosci 14:6144-6152.

Kotler M, Cohen H, Segman R, Gritsenko I, Nemanov L, Lerer B, Kramer I, Zer-Zion M, Kletz I, Ebstein RP (1997) Excess dopamine D4 receptor (D4DR) exon III seven repeat allele in opioid-dependent subjects. Mol Psychiatry 2:251-254.

Kuhn K, Meyer K, Nothen MM, Gansicke M, Papassotiropoulos A, Maier W (1999) Allelic variants of dopamine receptor D4 (D4DR) and serotonin receptor 5HT2c (HTR2c) and temperament factors: replication tests. Am J Med Genet 88:168-172.

LaHoste GJ, Swanson JM, Wigal SB, Glabe C, Wigal T, King N, Kennedy JL (1996) Dopamine D4 receptor gene polymorphism is associated with attention deficit hyperactivity disorder. Mol Psychiatry 1:121-124.

Lanau F, Zenner M, Civelli O, Hartman D (1997) Epinephrine and norepinephrine act as potent agonists at the recombinant human dopamine D4 receptor. J Neurochem 68:804-812.

Malhotra AK, Virkkunen M, Rooney W, Eggert M, Linnoila M, Goldman D (1996) The association between the dopamine D4 receptor (D4DR) 16 amino acid repeat polymorphism and novelty seeking. Mol Psychiatry 1:388-391.

Misslin R, Cigrand M (1986) Does neophobia necessarily imply fear or anxiety? Behav Proc 12:45-50.

Montgomery KC (1955) The relation between fear induced by novel stimulation and exploratory behavior. J Comp Physiol Psychol 48:254-260.

Montkowski A, Poettig M, Mederer A, Holsboer F (1997) Behavioral performance in three substrains of mouse strain 129. Brain Res $762: 12-18$

Mrzljak L, Bergson C, Pappy M, Huff R, Levenson R, Goldman-Rakic PS (1996) Localization of dopamine D4 receptors in GABAergic neurons of the primate brain. Nature 381:245-248.

Norton S (1977) Animal models in psychiatry and neurology. Oxford: Pergamon.

Nothen MM, Cichon S, Hemmer S, Hebebrand J, Remschmidt H, Lehmkuhl G, Poutska F, Schmidt M, Catalano M, Fimmers R, Korner J, Rietschel M, Propping P (1994) Human dopamine D4 receptor gene: frequent occurrence of a null allele and observation of homozygosity. Hum Mol Genet 3:2207-2212.

Overton P, Clark D (1992) Electrophysiological evidence that intrastriatally administered $N$-methyl-D-aspartate augments striatal dopamine tone in the rat. J Neural Transm 4:1-14.

Piazza PV, Deminiere JM, le Moal M, Simon H (1989) Factors that predict individual vulnerability to amphetamine self-administration. Science 29:1511-1513. 
Renner MJ, Dodson DL, Leduc PA (1992) Scopolamine suppresses both locomotion and object contact in a free-exploration situation. Pharmacol Biochem Behav 41:625-636.

Rubinstein M, Phillips TJ, Bunzow JR, Falzone TL, Dziewczapolski G, Zhang G, Fang Y, Larson JL, McDougall JA, Chester JA, Saez C, Pugsley TA, Gershanik O, Low MJ, Grandy DK (1997) Mice lacking dopamine D4 receptors are supersensitive to ethanol, cocaine, and methamphetamine. Cell 90:991-1001.

Shields PG, Lerman C, Audrain J, Bowman ED, Main D, Boyd NR, Caporaso NE (1998) Dopamine D4 receptors and the risk of cigarette smoking in African-Americans and Caucasians. Cancer Epidemiol Biomarkers Prev 7:453-458.
Vandenbergh DJ, Zonderman AB, Wang J, Uhl GR, Costa PT (1997) No association between novelty-seeking and dopamine D4 receptor (D4DR) exon III seven repeat alleles in Baltimore Longitudinal Study of Aging participants. Mol Psychiatry 2:417-419.

Van Hartesveldt C, Joyce JN (1986) Effects of estrogen on the basal ganglia. Neurosci Biobehav Rev 10:1-14.

Welker WI (1957) "Free" versus "forced" exploration of a novel situation by rats. Psychol Rep 3:95-108.

Westerink BHC, Santiago M, De Vries JB (1992) The release of dopamine from nerve terminals and dendrites of nigrostriatal neurons induced by excitatory amino acids in the conscious rat. Naunyn Schmiedebergs Arch Pharmacol 345:523-529. 